Article

\title{
Is There a Relationship between Transepidermal Water Loss and Microbial Biodiversity on the Skin?
}

\author{
Christopher Wallen-Russell 1,2 (D) \\ 1 Research Centre, Pavane Consultants Ltd., Reading, Berkshire RG1 5SB, UK; kit@pavane.co.uk; \\ Tel.: +44-781-596-0835 \\ 2 Information Services, University College London, Gower Street, London WC1E 6BT, UK
}

Received: 25 January 2019; Accepted: 6 March 2019; Published: 9 March 2019

\begin{abstract}
As described in previous work, TEWL (transepidermal water loss) is used as an indicator of skin barrier function and health by scientists at top research institutions. However, it is known to be unreliable because many other factors determine its value, such as humidity, temperature and moisture content of the skin. In this study, to help elucidate whether it is a good indicator of the health of skin, we used bivariate linear correlation analysis and the Pearson correlation coefficient to compare values of skin microbial biodiversity with TEWL. In 2017 in our previous work, microbial biodiversity was found to currently be the only reliable indicator of skin health. Diversity was also compared with moisture content and $\mathrm{pH}$, along with TEWL vs. moisture. All data was taken from the use of human participants in our previous work in 2018. Results showed no linear correlation between microbial biodiversity and TEWL rates or any of the other variables. This suggests the need for researchers to make conclusions about TEWL rates and their meaning with regards to skin function and health, with caution. Future work should consider the possibility of non-linear relationships, use larger datasets and mitigate against the effect of non-normally distributed data.
\end{abstract}

Keywords: transepidermal water loss; skin microbiome; skin microbiome biodiversity; biodiversity; skin barrier health; correlation; measure skin health; diversity

\section{Introduction}

As the world is only just beginning to understand the crucial role the skin plays in overall health, research into the skin microbiome is a quickly growing topic. A combination of the skin barrier and one's innate immunity forms the delicate balance needed to maintain healthy skin. A perturbation in this balance can lead to the host becoming more vulnerable to cutaneous infections and inflammatory diseases. The skin barrier acts as the first line of defence in humans, shielding the host from invading pathogens and environmental agents. Trans-epidermal-water-loss rate in human skin is used as a measuring tool in evaluating skin barrier function and health in diseased and damaged skin [1-5] and is commonly used by some academic institutions for this purpose [6]. Higher rates of TEWL are associated with weakened barrier function and condition, which can be due to physical and chemical changes, or conditions such as eczema, whereas decreased TEWL is said to indicate an unimpaired or recovered skin barrier [7-12]. Studies seemed to show an increase in TEWL on affected compared to clear areas on the skin of AD infant patients [13-16], however it is still being debated whether TEWL is linked to skin ailments in adults $[17,18]$. Moreover, conclusions about skin condition in vivo using TEWL are known to be unreliable as many other individual and environmental factors can impact its value [19-27], such as humidity, temperature [28-30], moisture content of the skin, sweat gland activity [31], metabolism [32] and other daily fluctuations [33]. It is evident that much work is needed to increase certainty about conclusions using TEWL rates, as they "should not be unconditionally ascribed to an alteration of skin barrier function [22]. 
New research elucidated the meaning of skin 'health' in our previous work [34], with discovery of what was described as the 'first and only reliable mechanism of measuring skin health using microbiome biodiversity'. When damaged or diseased, the skin always harbours a reduced diversity of microbial species compared to healthy or normal skin; the same trait as observed in other ecosystems across nature. Conversely, studies on TEWL produce inconsistent results. This discovery meant that the use of TEWL as an effective and reliable measure of skin damage and health could be tested. This study, therefore, performs bivariate linear correlation analysis on these variables using the Pearson correlation coefficient method $[35,36]$ to investigate whether a relationship between TEWL and microbial biodiversity exists. The relationship between biodiversity and $\mathrm{pH}$ and skin moisture; and TEWL and skin moisture was also tested to help knowledge of the factors affecting skin health. Healthier skin is associated with higher biodiversity, and lower TEWL rates, so if they are linked, we would expect to see a negative correlation. For $\mathrm{pH}$, moisture and TEWL vs. moisture, it is less clear what links may exist.

\section{Methods}

This study uses data acquired in previous work with The Medical University of Graz [6], within which the study design, interventions, study subjects and skin measurements, sample collection, DNA extraction and analytical and biometrical analysis are detailed. The data collected was used in this study to compare skin microbial diversity, $\mathrm{pH}$, TEWL and moisture content of the skin of the thirty-two volunteers who completed the four-week study, where three different face washes were used to test their effect on the skin microbiome. Skin measurements/swabs were taken at T1 (start of the trial, T2 (two weeks in) and T3 (end of the four-week study). However, it is not essential to the understanding of this study to provide exact details of the regimes and processes. Please refer to our previous work for an in-depth explanation of the methods in case of the need or want to replicate.

Human skin samples were taken non-invasively and handled with approval by and in accordance with the Ethic Commission at the Medical University of Graz. The Ethics Commission stated that no ethical concerns are raised by the methods applied and approved the following procedures without the need for an ethics vote. Informed verbal consent was obtained from each prior to the study. Samples were treated anonymously, and human material was not the focus point of this study. Microbial samples or data derived cannot be linked to a certain individual. The process of the experimentation was agreed upon by The Medical University of Graz, and ACIB (The Austrian Centre of Biotechnology), a not-for-profit research organisation through whom the funding application was made.

As an example of how TEWL is commonly used to determine 'skin health', the research team at The Medical University of Graz, based on the instructions from courage and khazaka, divided the skin samples into groups of 'skin health' based on TEWL measurements. The lowest value group was said to have 'very healthy' skin and values exceeding a certain level were said to be in 'critical' skin health.

\section{Data Analysis-Correlation and Distribution}

In the previous study [6], two alpha diversity indices were used to analyse the data: Chao1 and Richness. The average skin health of participants was said to be higher when higher biodiversity was observed. In this study Chao1 is used. The Chao1 index is believed to give the most representative description of the microbial diversity present on the skin. For a better description of how it manages this, and why it is preferred in this research, see our first paper [34] or previous work [37,38].

The data acquired in our previous work [6] was used to create graphs of Diversity vs. TEWL, Moisture and pH; and TEWL vs. Moisture. As measurements were taken at three different timepoints in the previous study (T1, T2 and T3) there were three graphs created to compare along with the combined data for all time points. The change in TEWL, diversity, skin moisture and pH from T1 to T2, T2 to T3 and T1 to T3 was plotted to investigate a link between changing data. Bivariate correlation analysis was performed which describes the strength of a linear association between two variables. The Pearson correlation coefficient, or ' $r$ ', was calculated for each data set $[35,36]$. 
Indicated in Section 3.6 is whether the correlation coefficients ' $r$ ' exceeds the value needed for a correlation to be observed $\left(r_{r e q}\right)$ in each dataset. This is obtained using the table of correlation coefficients displayed in Table 1 [39], where $r_{\text {req }}$ needed for correlation is shown at different degrees of freedom and probability levels. 'Degrees of Freedom' is the number of data points on any given graph, minus two.

Table 1. Table of correlation coefficients at varying degrees of freedom.

\begin{tabular}{ccc}
\hline \multirow{2}{*}{ Degrees of Freedom } & \multicolumn{2}{c}{ Probability, $\boldsymbol{p}$} \\
\cline { 2 - 3 } & $\mathbf{0 . 0 5}$ & $\mathbf{0 . 0 1}$ \\
\hline 1 & 0.997 & 1 \\
5 & 0.755 & 0.875 \\
10 & 0.576 & 0.708 \\
15 & 0.482 & 0.606 \\
20 & 0.423 & 0.457 \\
25 & 0.381 & 0.487 \\
30 & 0.349 & 0.449 \\
90 & 0.205 & 0.267 \\
100 & 0.195 & 0.254 \\
\hline
\end{tabular}

The JMP statistical analysis programme was used to form graphs in Section 3. The remaining graphs were created in Excel. All the data sets were tested for normal distribution, primarily by performing a Shapiro-Wilk test, which is useful for small to medium sample size $(\mathrm{n}<300)$ [40]. Small $p$-values $(p<0.05)$ reject the null hypothesis $\left(\mathrm{H}_{0}=\right.$ The data is from a normal distribution). The observation of histograms, normal Q-Q and box plots was also used to test for normally distributed data, with the results shown in Section 3.1. It is noted that, due to measurement principle of TEWL, it is an example of skewed distribution, so non-normality should be observed. The tests for normality were made because the Pearson correlation coefficient can be influenced by data distribution and therefore non-normal distributions could be a source of error to consider in future work.

\section{Results}

\subsection{Sample Characteristics}

A Shapiro-Wilk test $(p>0.05)$ [41,42], a visual inspection of their histograms, normal Q-Q plots and box plots showed that the exam scores were approximately normally distributed for the datasets used in this study. An example using data from this study of a histogram and normal Q-Q plot for approximately normal and non-normal data is shown in Figure 1. Normally distributed data should plot close to the diagonal straight line in the Q-Q plot and should have an approximate symmetrical bell-curve shape in the histogram.

Table 2 shows the Shapiro-Wilk test of normality p-values for all datasets, along with whether they accept or reject the null hypothesis (that the data is normally distributed). It is evident from Table 2 that the TEWL datasets are all defined as non-normal using the Shapiro-Wilk test. The datasets for $\mathrm{pH}$ are all deemed normally distributed while the other two are split. 
(A)

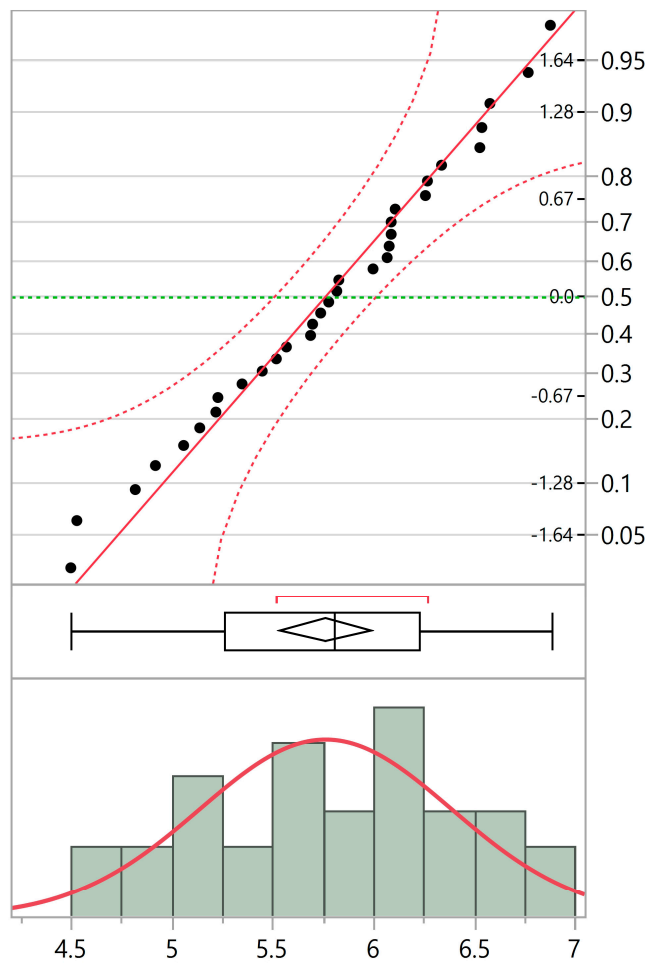

(B)

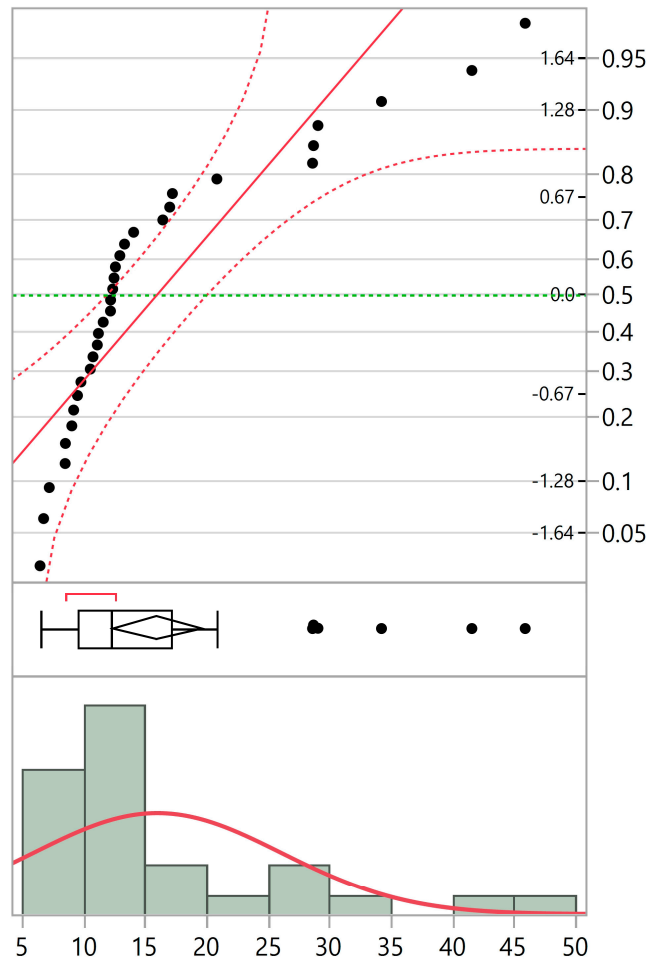

Figure 1. (A) shows a $Q-Q$ plot and histogram for an approximately normal distribution, with a Shapiro-Wilk test $p$-value of 0.741 . (B) shows a Q-Q plot and histogram of an approximately non-normal distribution, with a Shapiro-Wilk test $p$-value of $<0.0001$.

Table 2. $P$-values for the Shapiro-Wilk test performed for all datasets. Bold and underlined values show where the null hypothesis is accepted and data is normally distributed.

\begin{tabular}{cccccccc}
\hline Measurement & T1 & T2 & T3 & Combined & T1 to T2 & T1 to T3 & T2 to T3 \\
\hline Diversity & 0.0042 & $\underline{0.307}$ & $\underline{0.768}$ & $\underline{0.0925}$ & 0.0001 & $<0.0001$ & $\underline{0.0741}$ \\
TEWL & $<0.0001$ & $<0.0001$ & $<0.0001$ & $<0.0001$ & $<0.0001$ & 0.0096 & $<0.0001$ \\
Moisture & $\underline{0.397}$ & 0.001 & $\underline{0.418}$ & 0.0002 & 0.0001 & $\underline{0.52}$ & $\underline{0.161}$ \\
pH & $\underline{0.302}$ & $\underline{0.741}$ & $\underline{0.261}$ & $\underline{0.109}$ & $\underline{0.817}$ & - & $\underline{0.0577}$ \\
\hline
\end{tabular}

\subsection{Diversity vs. TEWL}

Figure 2 shows the microbial diversity against TEWL on the skin of the human volunteers at each timepoint of measuring. Figure 3 shows the change in both these variables plotted against each other. Due to the number of data points and using Table 1, the minimum correlation coefficient needed for a statistical relationship to exist is $r_{\text {req }}=0.349(p=0.05)$ for all graphs in this section apart from Figure 2D, where $r_{\text {req }}=0.201(p=0.05)$. None of the graphs in this section displayed an $r$-value higher than these, indicating there is no relationship between the variables. The clear outliers, and data distribution for TEWL being characteristically skewed and non-normal (Table 2) in this section could both have affected the value of $\mathrm{r}$ and will need to be scrutinized in future work. 

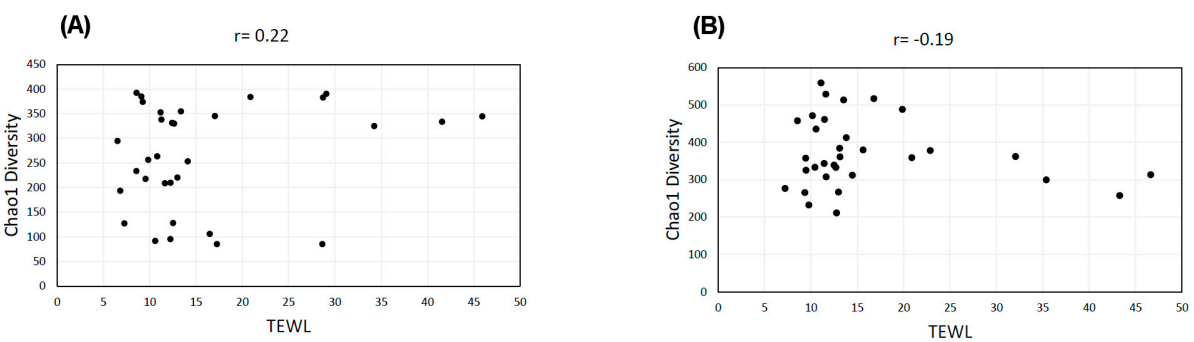
(C)

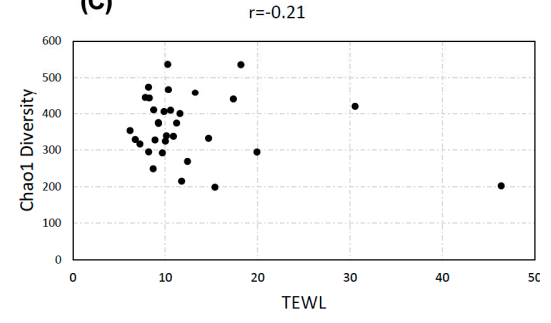

(D)

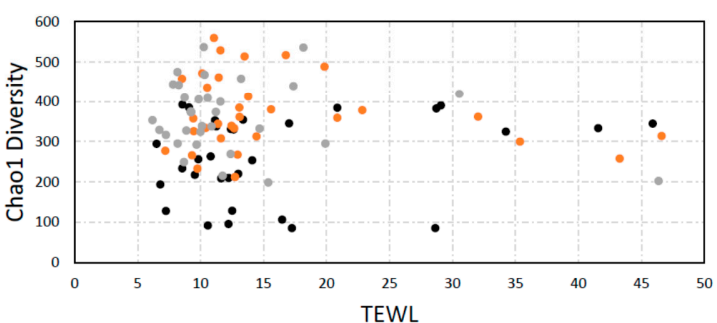

Figure 2. Diversity against TEWL graphs. Graph (A) shows T1 where $r=0.22$. Graph (B) shows $\mathrm{T} 2$ where $\mathrm{r}=-0.19$. Graph $(\mathbf{C})$ shows T3 where $\mathrm{r}=-0.21$; and Graph $(\mathbf{D})$ shows T1, T2 and T3 all combined where $r=-0.063$.

(A)

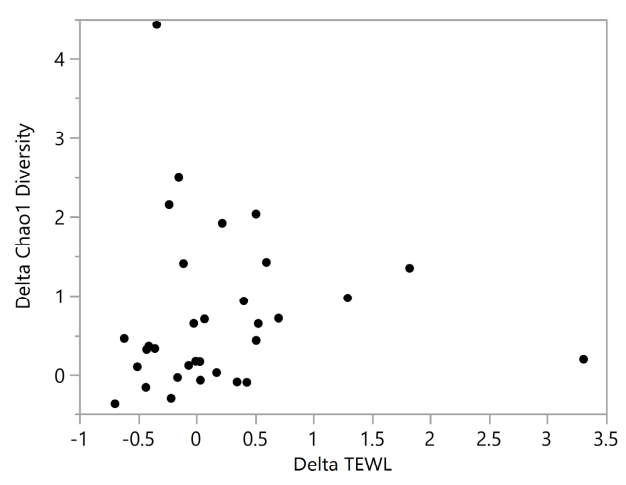

(B)

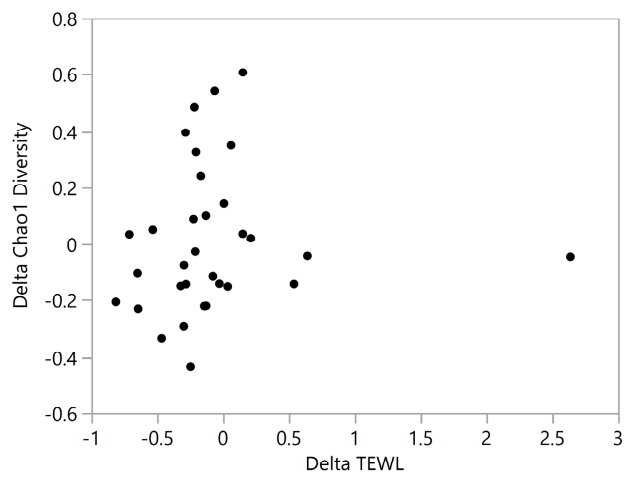

(C)

Figure 3. Change in Chao1 Diversity against change in TEWL. (A) shows T1 to T2 where $\mathrm{r}=0.025$. (B) shows $\mathrm{T} 2$ to $\mathrm{T} 3$ where $\mathrm{r}=-0.089$. (C) Shows T1 to T3 where $\mathrm{r}=0.084$. All correlation coefficients, or ' $r$ ' values, are shown in Table 3.

\subsection{Diversity vs. Moisture}

Figure 4 shows human skin microbial diversity of the volunteers plotted against their average skin moisture at each timepoint. Figure 5 shows the change in the same variables between different timepoints plotted against each other. Two out of seven graphs (Figure 4B,D) display a correlation $(\mathrm{r}=-0.43$ and $\mathrm{r}=-0.32$ respectively), and both these correlations are not only visible at $p=0.05$ level 
but $p=0.01$ too, rendering them stronger. When outliers were excluded, the value of ' $r$ ' changed drastically. This is an example of Pearson's coefficient being very sensitive to outliers. For example, when the outlier in the bottom right of Graph (C) in Figure 4 was removed, it gave the data a strong positive correlation, a change from $r=-0.040$; to $r=0.49(p<0.01)$.
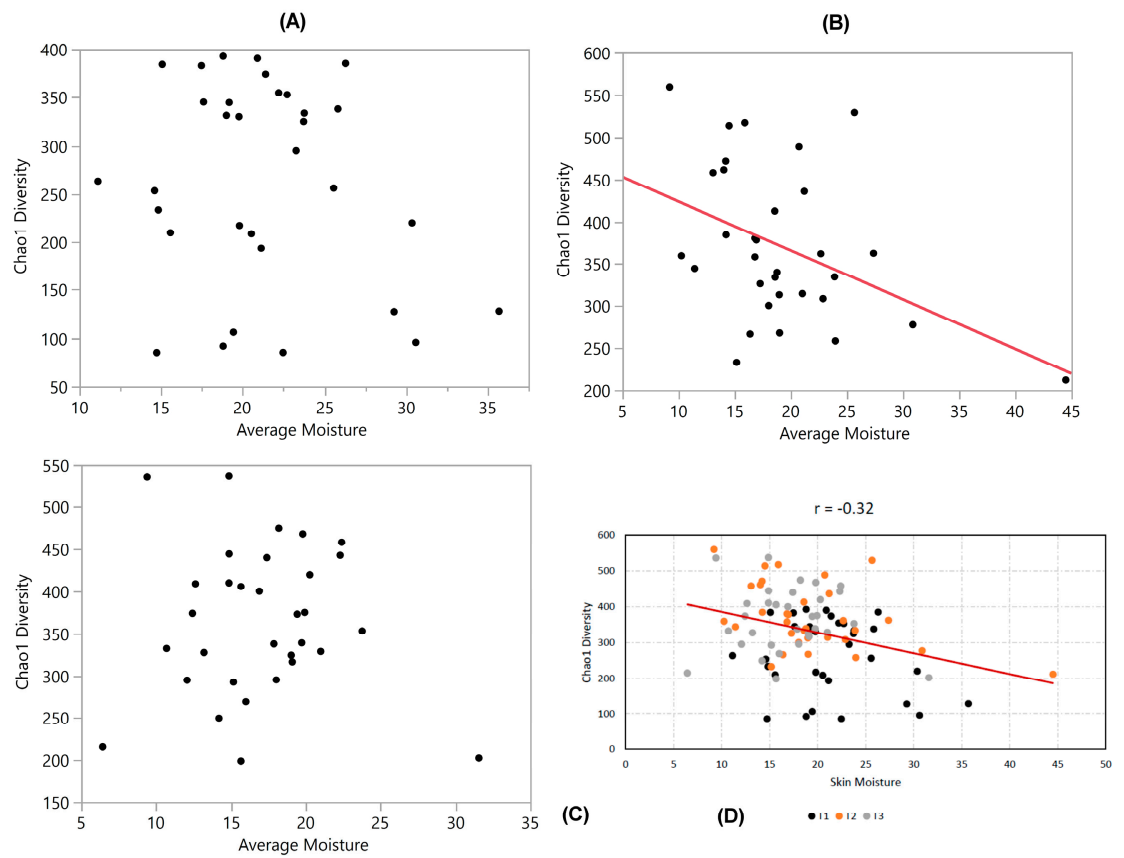

(C)

(D)

Figure 4. Chao1 diversity plotted against skin moisture for all time points. (A) shows T1 where $\mathrm{r}=-0.2$. (B) shows T2 where $r=-0.43$ and a red correlation line of best fit. (C) shows T3 where $r=0.04$. (D) shows $\mathrm{T} 1, \mathrm{~T} 2$ and $\mathrm{T} 3$ combined with a correlation line of best fit where $\mathrm{r}=-0.32$. Black points are T1, orange T2 and grey $\mathrm{T} 3$.

(A)
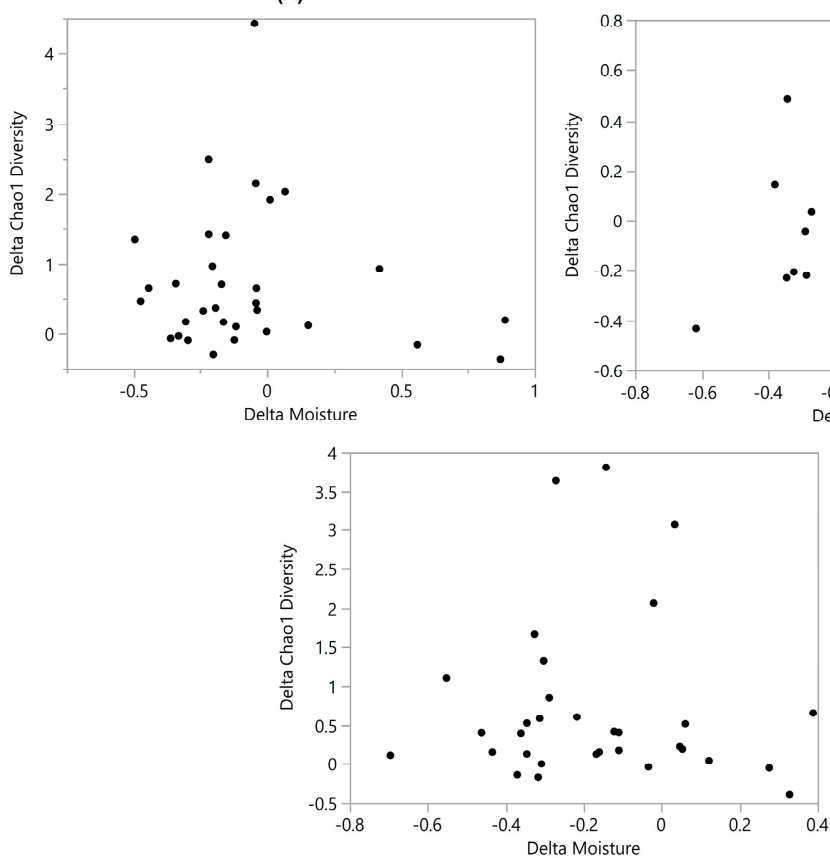

(B)

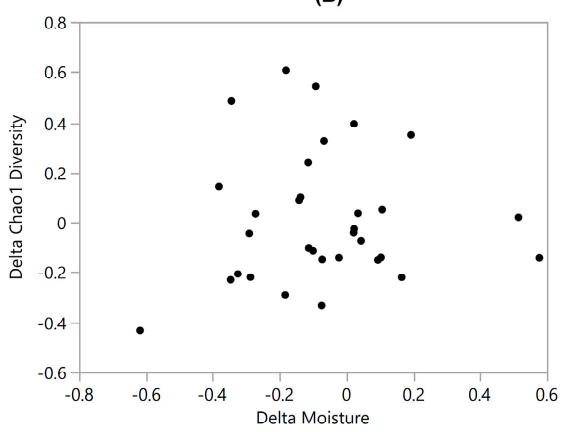

(C)

Figure 5. Delta (change in) Chao1 diversity against delta skin moisture. (A) shows T1 to T2 where $\mathrm{r}=-0.12$. (B) shows T2 to T3 where $r=-0.038$. (C) shows T1 to T3 where $r=0.056$. All correlation coefficients, or ' $r$ ' values, are shown in Table 3. 


\subsection{Diversity vs. $p H$}

Figure 6 shows human skin microbial diversity of the volunteers plotted against their average skin $\mathrm{pH}$ at each timepoint. Figure 7 shows the change in the same variables between different timepoints plotted against each other. One out of seven graphs (Figure 6D) displays a correlation $(r=0.22$ and $p=0.05)$, suggesting there is no strong evidence for a relationship between the variables.

(A)
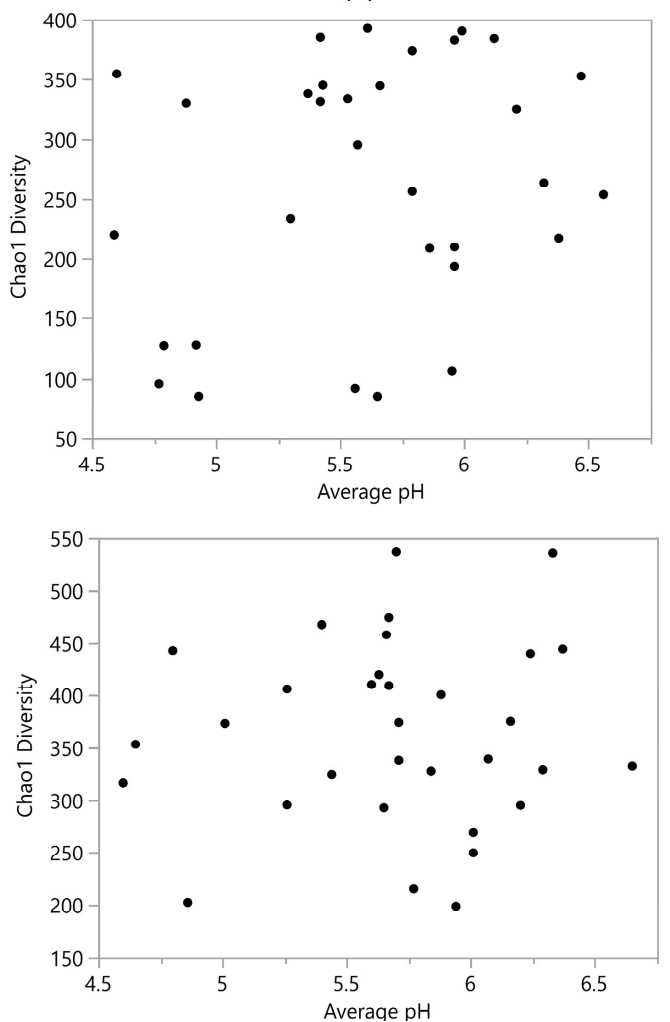

(B)
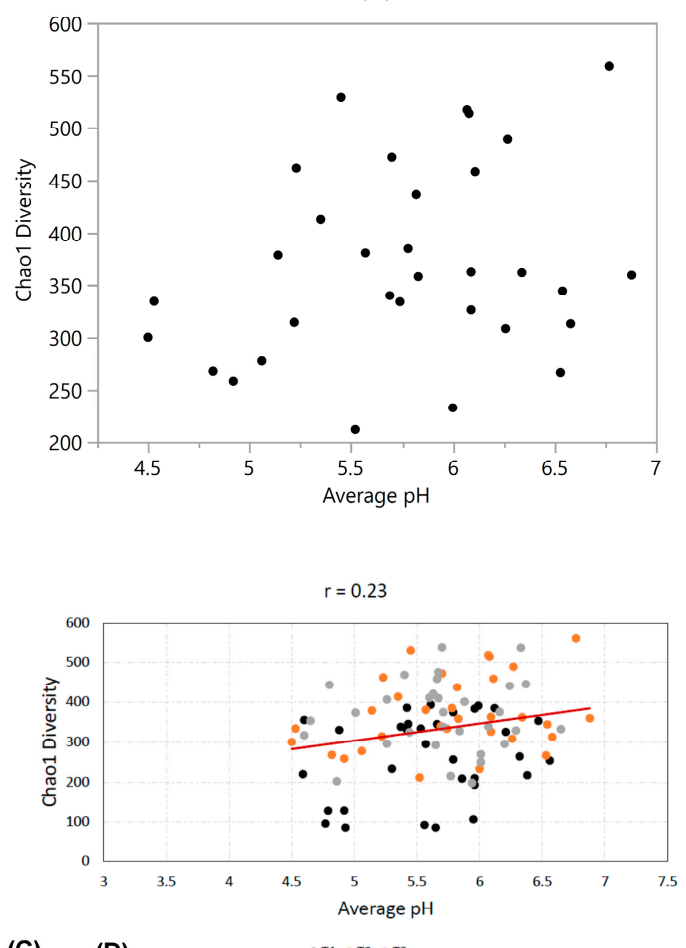

(D)

Figure 6. Chao1 diversity plotted against $\mathrm{pH}$. Graph $(\mathbf{A})$ shows $\mathrm{T} 1$ where $\mathrm{r}=0.24$. Graph $(\mathbf{B})$ shows $\mathrm{T} 2$ where $r=0.26$. Graph $(\mathbf{C})$ shows T3 where $r=0.071$. Graph $(\mathbf{D})$ shows T1, T2 and T3 combined where $\mathrm{r}=0.22$.

(A)

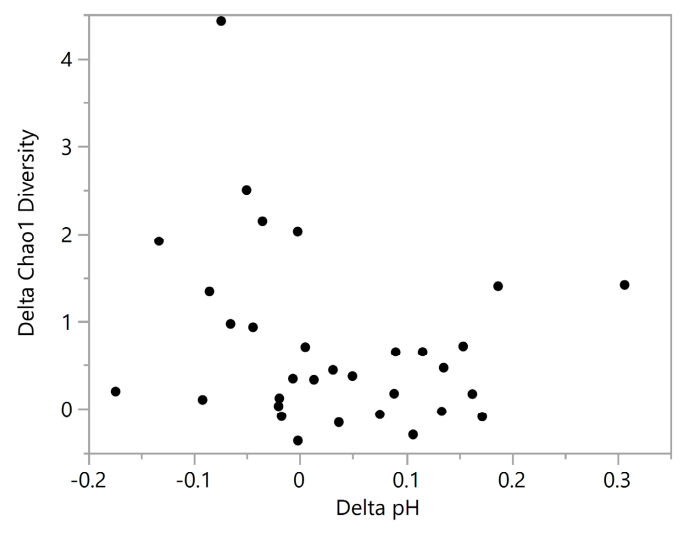

(B)

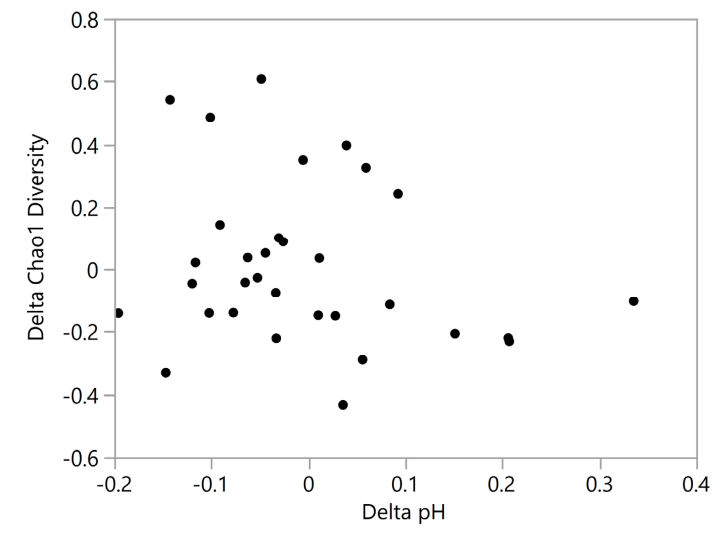

Figure 7. Delta (change in) Chao1 diversity plotted against delta $\mathrm{pH}$. (A) shows $\mathrm{T} 1$ to $\mathrm{T} 2$ where $\mathrm{r}=-0.24$. (B) shows T2 to T3 where $r=-0.23$. All correlation coefficients, or ' $r$ ' values, are shown in Table 3. 


\subsection{TEWL vs. Skin Moisture}

Figure 8 shows human skin TEWL of the volunteers plotted against their average skin moisture at each timepoint. Figure 9 shows the change in the same variables between different timepoints plotted against each other. No graph in this section displays a correlation, again suggesting there is no relationship between the variables.

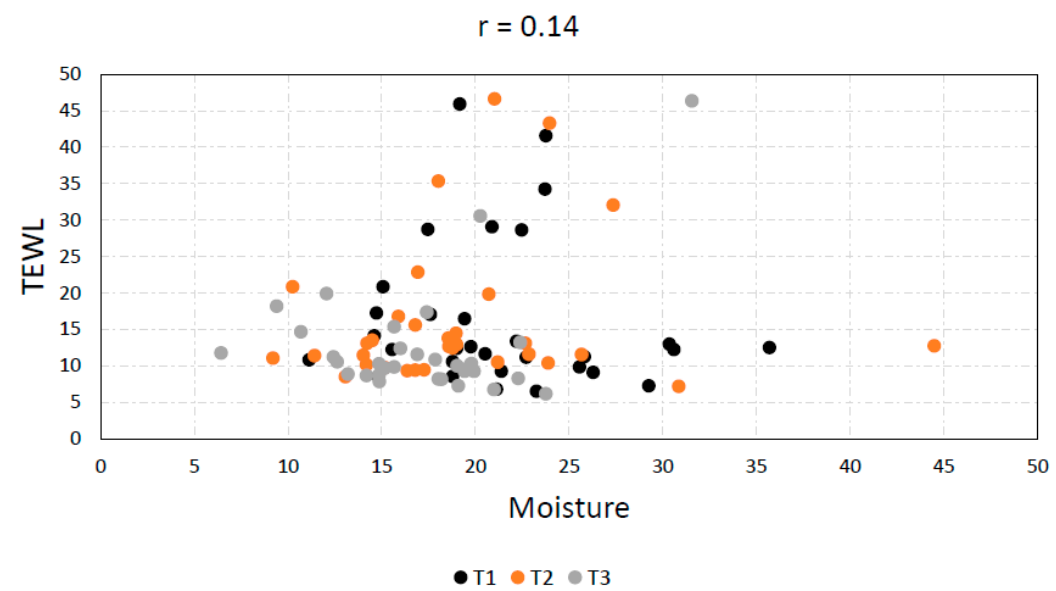

Figure 8. TEWL plotted against moisture for all timepoints (T1, T2 and T3). For T1 (black), $\mathrm{r}=-0.082$. For T2 (orange) $r=0.12$. For T3 (grey) $r=0.34$. For all combined $r=0.14$. All correlation coefficients, or ' $r$ ' values, are shown in Table 3.

(A)

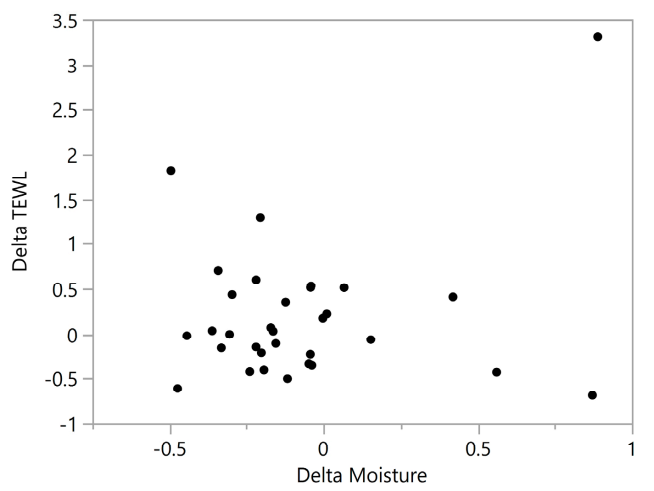

(B)

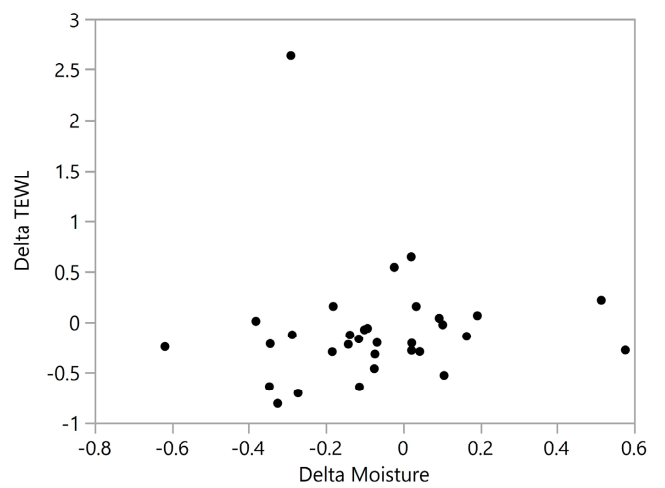

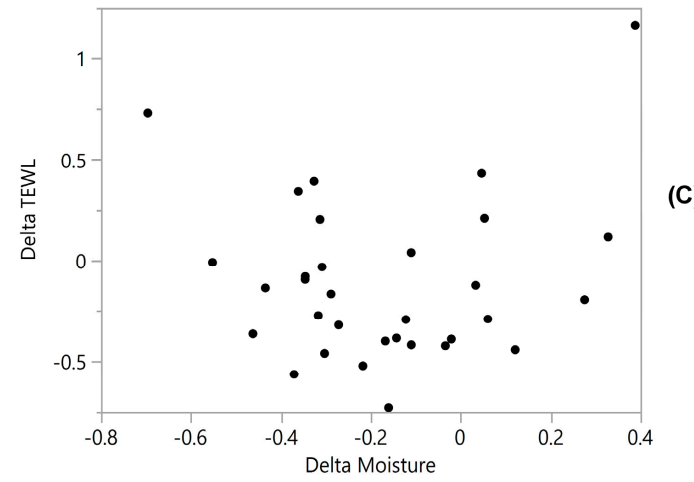

Figure 9. Delta (change in) TEWL plotted against delta moisture. (A) shows T1 to T2 where $\mathrm{r}=0.21$. (B) shows T2 to T3 where $r=0.096$. (C) shows T1 to T3 where $r=0.022$. All correlation coefficients, or ' $r$ ' values, are shown in Table 3. 


\subsection{Correlation Coefficients (' $r$ ' Values)}

Table 3 shows a breakdown of the ' $r$ ' values for each graph seen in Sections 3.2-3.5. For the 'combined' graphs, $r_{\text {req }}=0.201$. For all others $r_{\text {req }}=0.349$. $r_{\text {req }}$ is the ' $r$ ' value required for a statistically significant correlation to be observed and is obtained from Table 1 using degrees of freedom. There are 96 data points on the combined compared to 32 on the others, meaning that the degrees of freedom is much higher in the 'combined' graphs and the threshold value of ' $r$ ' is lower.

Table 3. ' $r$ ' values for Pearson's correlation coefficient for each graph displayed in Section 3. The underlined values exceed $r_{\text {req. Values with an asterisk }}\left(^{*}\right)$ show a higher probability of $p=0.01$, otherwise $p=0.05$.

\begin{tabular}{cccccccc}
\hline Graph & T1 & T2 & T3 & Combined & T1 to T2 & T1 to T3 & T2 to T3 \\
\hline Diversity vs. TEWL & 0.22 & -0.19 & -0.21 & -0.063 & 0.025 & -0.089 & 0.084 \\
Diversity vs. & -0.2 & $\underline{-0.43^{*}}$ & -0.04 & $\underline{-0.32 *}$ & -0.12 & -0.038 & 0.056 \\
Moisture & 0.24 & 0.26 & 0.071 & $\underline{0.22}$ & -0.24 & - & -0.23 \\
Diversity vs. pH & -0.082 & 0.12 & 0.34 & 0.14 & 0.21 & 0.096 & 0.022 \\
TEWL vs. Moisture & -0.14 &
\end{tabular}

\section{Discussion}

Overall, a statistically significant correlation was evident in three of 28 data sets. A relative increase in microbial diversity (using the Chao1 index) is associated with healthier skin [34], just as a decrease in TEWL rates is linked to a strengthened skin barrier. If there is a linear relationship between diversity and TEWL rates, a negative correlation should have been observed. No linear correlation was observed as none of the datasets in Section 3.2 had a value of $r$ exceeding $r_{\text {req }}$ needed for correlation. The non-normality of all TEWL data could have influenced correlation results.

The relationship between diversity and moisture on the skin had the highest proportion of graphs displaying a correlation. Two of the seven graphs showed a statistically significant correlation, and only one ' $r$ ' value is not negative. This suggests there is a larger negative correlation than between diversity and TEWL, where no correlation was observed, however, it is still very weak and should be investigated further. A correlation was observed in the 'combined' graph for diversity and $\mathrm{pH}$.

It was proposed that absolute TEWL values matter less than changes over time [43], however our results for changes in TEWL compared to changes in diversity (to solve this problem) show no correlations. This is also true for the other comparisons. In future work on the topic, more should be done to keep constant other factors which affect TEWL, to isolate TEWL rates and diversity as the only two forcing factors. This would be possible with some environmental characteristics, however innate bodily functions such as metabolism and sweat gland activity would pose more of a challenge. It should also be performed on participants with ranging states of healthy and damaged skin, as this may give more disparity in TEWL values.

Pearson's correlation coefficient is sensitive to both outliers and data distribution [35,44-47] and is a measure of linear bivariate correlation, however it does not require normal distribution to run. The more dissimilar the distribution shapes between $X$ and $Y$ variables, the lower the maximum value of ' $r$ ' [48,49]. Therefore, as TEWL data has non-normal distribution, this could have affected the value of ' $r$ '. A nonparametric equivalent to Pearson's correlation such as the use of the Spearman rho correlation method [35,50], which is more robust to outliers and distribution, should be used in the future to mitigate against the effect of outliers, non-normally distributed data and to assess non-linear associations. These tests would give more meaningful results for data found to be outside the criteria for approximate normal distribution. A larger sample size should be used in the future so the use of other normality tests such as kurtosis and skewness can be performed, using standard error to find $z$ scores which should fall between +2 and -2 for normal distribution [51-53]. When using visual methods such as Q-Q plots and histograms, larger datasets are needed for increased accuracy. Larger sample sizes will also be able to provide a more accurate depiction of the relationships involved. 
The Shapiro-Wilk test for normality is also shown to be sensitive to outliers in this study. The removal of one distant outlier from a dataset changed the $p$-value from $<0.0001$ to 0.357 . This could indicate a weakness in the Shapiro-Wilk test.

\section{Conclusions}

This study showed no evidence of a linear correlation between the skin's microbial diversity and TEWL rates. Taking previous work on the skin-health measuring mechanism using microbial biodiversity to be a reliable indicator of skin health, this suggests the need to take conclusions about TEWL rates and its reliability in determining the health of the skin barrier, with caution. The relationship between diversity and skin moisture showed the strongest signs of a correlation. A firm linear relationship between diversity and $\mathrm{pH}$; or TEWL and moisture, was not found. The findings could affect how 'skin health' groupings are made in future studies and dissuade research institutions from interpreting too much from TEWL rates. Future work should statistically determine if there are non-linear relationships present which could account for the lack of linear correlation and use more participants with damaged skin.

Funding: The original study from which this paper was created was funded by a FemTech grant for 'women in science' which was organized and applied for through ACIB (Austrian Centre for Industrial Biotechnology). This was put towards the original laboratory work.

Acknowledgments: This work was supported by Pavane Consultants Ltd. I would like to thank my twin, Sam Wallen Russell, whose knowledge of statistical methods in mathematics proved very useful.

Conflicts of Interest: Christopher Wallen-Russell is an employee of research and development company Pavane Consultants Ltd., who commissioned the paper, and director of JooMo Ltd. Skin health company, JooMo Ltd., holds the exclusive license for the manufacturing, marketing and sale of Pavane Consultant Ltd.'s products. As licence holder for the JooMo Ltd. range of skin health products, Pavane Consultants Ltd. are interested in determining how skin health can be measured and which products in the environment have caused the huge increase in skin allergy problems in the past 75 years.

\section{References}

1. Lamke, L.-O.; Nilsson, G.E.; Reithner, H.L. Insensible perspiration from the skin under standardized environmental conditions. Scand. J. Clin. Lab. Investig. 1977, 37, 325-331. [CrossRef]

2. Nilsson, G.E. Measurement of water exchange through skin. Med. Biol. Eng. Comput. 1977, 15, 209-218. [CrossRef] [PubMed]

3. Lotte, C.; Rougier, A.; Wilson, D.R.; Maibach, H.I. In vivo relationship between transepidermal water loss and percutaneous penetration of some organic compounds in man: Effect of anatomic site. Arch. Dermatol. Res. 1987, 279, 351-356. [CrossRef] [PubMed]

4. Freeman, S.; Maibach, H. Study of irritant contact dermatitis produced by repeat patch test with sodium lauryl sulfate and assessed by visual methods, transepidermal water loss, and laser Doppler velocimetry. J. Am. Acad. Dermatol. 1988, 19, 496-502. [CrossRef]

5. Nicander, I.; Ollmar, S.; Eek, A.; Rozell, B.L. Emtestaml Correlation of impedance response patterns to histological findings in irritant skin reactions induced by various surfactants. Br. J. Dermatol. 1996, 134, 221-228. [CrossRef] [PubMed]

6. Wallen-Russell, C.; Wallen-Russell, C. The Role of Every-Day Cosmetics in Altering the Skin Microbiome: A Study Using Biodiversity. Cosmetics 2018, 6, 2. [CrossRef]

7. Lamaude, E.; Schallaw, W. Influence of UV irradiation on penetration of hydrocortisone. In vivo study in hairless rat skin. Br. J. Dermatol. 1984, 111, 152-157. [CrossRef]

8. Van der Valk, P.G.; Maibach, H.I. A functional study of the skin barrier to evaporative water loss by means of repeated cellophane-tape stripping. Clin. Exp. Dermatol. 1990, 15, 180-182. [CrossRef]

9. Lévêque, J.L.; de Rigal, J.; Saint-Léger, D.; Billy, D. How Does Sodium Lauryl Sulfate Alter the Skin Barrier Function in Man? A Multiparametric Approach. Skin Pharm. Physiol. 1993, 6, 111-115. [CrossRef]

10. Boer, M.; Duchnik, E.; Maleszka, R.; Marchlewicz, M. Structural and biophysical characteristics of human skin in maintaining proper epidermal barrier function. Postepy Dermatol. Alergol. 2016, 33, 1-5. [CrossRef] 
11. Tagami, H.; Kobayashi, H.; Zhen, X.-S.; Kikuchi, K. Environmental Effects on the Functions of the Stratum Corneum. J. Investig. Dermatol. Symp. Proc. 2001, 6, 87-94. [CrossRef] [PubMed]

12. Kligman, A.M. Corneobiology and Corneotherapy-A final chapter. Int. J. Cosmet. Sci. 2011, 33, $197-209$. [CrossRef] [PubMed]

13. Giusti, F.; Martella, A.; Bertoni, L.; Seidenari, S. Skin Barrier, Hydration, and pH of the Skin of Infants Under 2 Years of Age. Pediatr. Dermatol. 2001, 18, 93-96. [CrossRef] [PubMed]

14. Chamlin, S.L.; Kao, J.; Frieden, I.J.; Sheu, M.Y.; Fowler, A.J.; Fluhr, J.W.; Williams, M.L.; Elias, P.M. Ceramide-dominant barrier repair lipids alleviate childhood atopic dermatitis: Changes in barrier function provide a sensitive indicator of disease activity. J. Am. Acad. Dermatol. 2002, 47, 198-208. [CrossRef] [PubMed]

15. Horimukai, K.; Morita, K.; Narita, M.; Kondo, M.; Kabashima, S.; Inoue, E.; Sasaki, T.; Niizeki, H.; Saito, H.; Matsumoto, K.; et al. Transepidermal water loss measurement during infancy can predict the subsequent development of atopic dermatitis regardless of filaggrin mutations. Allergol. Int. 2016, 65, 103-108. [CrossRef]

16. Kelleher, M.; Dunn-Galvin, A.; Hourihane, J.O.; Murray, D.; Campbell, L.E.; McLean, W.H.I.; Irvine, A.D. Skin barrier dysfunction measured by transepidermal water loss at 2 days and 2 months predates and predicts atopic dermatitis at 1 year. J. Allergy Clin. Immunol. 2015, 135, 930-935. [CrossRef]

17. Pinto, P.; Rosado, C.; Parreirão, C.; Rodrigues, L.M. Is there any barrier impairment in sensitive skin?: A quantitative analysis of sensitive skin by mathematical modeling of transepidermal water loss desorption curves. Skin Res. Technol. 2011, 17, 181-185. [CrossRef]

18. Angelova-Fischer, I.; Wuthe, D.; Zillikens, D.; Kahle, B. Noninvasive bioengineering assessment of the skin barrier function in patients with chronic venous insufficiency. Br. J. Dermatol. 2010, 162, 1071-1075. [CrossRef]

19. Plessis, J.; Stefaniak, A.; Eloff, F.; John, S.; Agner, T.; Chou, T.-C.; Nixon, R.; Steiner, M.; Franken, A.; Kudla, I.; et al. International guidelines for the in vivo assessment of skin properties in non-clinical settings: Part 2. transepidermal water loss and skin hydration. Skin Res. Technol. 2013, 19, 265-278. [CrossRef]

20. Darlenski, R.; Sassning, S.; Tsankov, N.; Fluhr, J.W. Non-invasive in vivo methods for investigation of the skin barrier physical properties. Eur. J. Pharm. Biopharm. 2009, 72, 295-303. [CrossRef]

21. Rogiers, V.; EEMCO Group. EEMCO guidance for the assessment of transepidermal water loss in cosmetic sciences. Skin Pharm. Appl. Skin Physiol. 2001, 14, 117-128. [CrossRef] [PubMed]

22. Chilcott, R.P.; Dalton, C.H.; Emmanuel, A.J.; Allen, C.E.; Bradley, S.T. Transepidermal Water Loss Does Not Correlate with Skin Barrier Function In Vitro. J. Investig. Dermatol. 2002, 118, 871-875. [CrossRef]

23. Darlenski, R.; Fluhr, J.W. Influence of skin type, race, sex, and anatomic location on epidermal barrier function. Clin. Dermatol. 2012, 30, 269-273. [CrossRef]

24. Muizzuddin, N.; Hellemans, L.; Van Overloop, L.; Corstjens, H.; Declercq, L.; Maes, D. Structural and functional differences in barrier properties of African American, Caucasian and East Asian skin. J. Dermatol. Sci. 2010, 59, 123-128. [CrossRef] [PubMed]

25. Ramos-e-Silva, M.; da Silva Carneiro, S.C. Elderly skin and its rejuvenation: Products and procedures for the aging skin. J. Cosmet. Dermatol. 2007, 6, 40-50. [CrossRef] [PubMed]

26. Maibach, H.; Honari, G.; Honari, G.; Maibach, H. Skin Structure and Function. Appl. Derm. 2014, 1-10. [CrossRef]

27. Akdeniz, M.; Gabriel, S.; Lichterfeld-Kottner, A.; Blume-Peytavi, U.; Kottner, J. Transepidermal water loss in healthy adults: A systematic review and meta-analysis update. Br. J. Dermatol. 2018, 179, 1049-1055. [CrossRef] [PubMed]

28. Blank, I.H.; Scheuplein, R.J. Transport into and within the skin. Br. J. Dermatol. 1969, 81, 4-10. [CrossRef]

29. Mathias, C.T.; Wilson, D.M.; Maibach, H.I. Transepidermal Water Loss as a Function of Skin Surface Temperature. J. Investig. Dermatol. 1981, 77, 219-220. [CrossRef] [PubMed]

30. Grice, K.; Sattar, H.; Sharratt, M.; Baker, H. Skin Temperature and Transepidermal Water Loss. J. Investig. Dermatol. 1971, 57, 108-110. [CrossRef]

31. Pinnagoda, J.; Tupkek, R.A.; Agner, T.; Serup, J. Guidelines for transepidermal water loss (TEWL) measurement. Contact Dermat. 1990, 22, 164-178. [CrossRef]

32. Kao, J.; Hall, J.; Shugart, L.R.; Holland, J.M. An in vitro approach to studying cutaneous metabolism and disposition of topically applied xenobiotics. Toxicol. Appl. Pharmacol. 1984, 75, 289-298. [CrossRef] 
33. Chilcott, R.P.; Farrar, R. Biophysical measurements of human forearm skin in vivo: Effects of site, gender, chirality and time. Skin Res. Technol. 2000, 6, 64-69. [CrossRef] [PubMed]

34. Wallen-Russell, C.; Wallen-Russell, S. Meta Analysis of Skin Microbiome: New Link between Skin Microbiota Diversity and Skin Health with Proposal to Use This as a Future Mechanism to Determine Whether Cosmetic Products Damage the Skin. Cosmetics 2017, 4, 14. [CrossRef]

35. Mukaka, M.M. Statistics corner: A guide to appropriate use of correlation coefficient in medical research. Malawi Med. J. 2012, 24, 69-71.

36. Rodgers, J.L.; Nicewander, W. Thirteen Ways to Look at the Correlation Coefficient. Am. Stat. 1987, 42, 59-66. [CrossRef]

37. Chao, A. Nonparametric Estimation of the Number of Classes in a Population Nonparametric Estimation of the Number of Classes in a Population. Scand. J. 1984, 11, 265-270.

38. Colwell, R.K.; Coddington, J.A. Estimating terrestrial biodiversity through extrapolation. Philos. Trans. R. Soc. 1994, 345, 101-118.

39. Sokal, R.R.; Rohlf, F.J. Biometry: The Principles and Practice of Statistics in Biological Research; W.H. Freeman: New York, NY, USA, 1995.

40. Kim, H.-Y. Statistical notes for clinical researchers: Assessing normal distribution (2) using skewness and kurtosis. Restor. Dent. Endod. 2013, 38, 52-54. [CrossRef]

41. Mohd Razali, N.; Bee Wah, Y. Power comparisons of Shapiro-Wilk, Kolmogorov-Smirnov, Lilliefors and Anderson-Darling tests. J. Stat. Model. Anal. 2011, 2, 13-14.

42. Shapiro, S.S.; Wilk, M.B. An Analysis of Variance Test for Normality (Complete Samples). Biometrika 1965, 52, 591. [CrossRef]

43. Baran, R.; Maibach, H.I. Textbook of Cosmetic Dermatology; CRC Press: Boca Raton, FL, USA, 2017; 594p.

44. Devlins, J.; Gnanadesikan, R.; Kettenring, J.R. Robust estimation and outlier detection with correlation coefficients. Biometrika 1975, 62, 531-545. [CrossRef]

45. Huber, P.J. Robust Statistics Hoboken; John Wiley \& Sons, Inc.: Hoboken, NJ, USA, 1981.

46. Kim, Y.; Kim, T.-H.; Ergün, T. The instability of the Pearson correlation coefficient in the presence of coincidental outliers. Financ. Res. Lett. 2015, 13, 243-257. [CrossRef]

47. Glass, G.V.; Hopkins, K.D. Statistical Methods in Education and Psychology, 3rd ed.; Allyn \& Bacon: Boston, MA, USA, 1996.

48. Carroll, J.B. The Nature of the Data, or How to Choose a Correlation Coefficient. Psychometrika 1961, 26, 347-372. [CrossRef]

49. Nunnally, J.C.; Bernstein, I.H. Psychometric Theory, 3rd ed.; McGraw-Hil: New York, NY, USA, 1994.

50. Caruso, J.C.; Cliff, N. Empirical Size, Coverage, and Power of Confidence Intervals for Spearman's Rho. Educ. Psychol. Meas. 1997, 57, 637-654. [CrossRef]

51. Cramer, D. Fundamental Statistics for Social Research: Step-by-Step Calculations and Computer Techniques Using SPSS for Windows New York; Routledge: New York, NY, USA, 1998.

52. Cramer, D.; Howitt, D. The Sage Dictionary of Statistics: A Practical Resource for Students in the Social Sciences; SAGE Publications: Thousand Oaks, CA, USA, 2004; 188p.

53. Doane, D.P.; Seward, L.E. Measuring Skewness: A Forgotten Statistic? J. Stat. Educ. 2011, 19. [CrossRef]

(C) 2019 by the author. Licensee MDPI, Basel, Switzerland. This article is an open access article distributed under the terms and conditions of the Creative Commons Attribution (CC BY) license (http://creativecommons.org/licenses/by/4.0/). 